\title{
A Study on the Introduction of Home-Based Physical Therapy for Patients with Cerebrovascular Disease
}

\author{
Gyu-Yong Kim', Chang-Sik Ahn², Hye-Won Jeon ${ }^{3}$ \\ ${ }^{1}$ Gangnam-gu Haengbok Hospital, Seoul; ${ }^{2}$ Department of Physical Therapy, Faculty of Health Science, Eulji University, Seongnam; ${ }^{3}$ Rebabilitation \\ Research institue, Korea National Rebabilitation, Seoul, Korea
}

Purpose: This study was conducted in order to present basic policy data for introduction of a home-based physical therapy (HBPT) policy. Methods: The study surveyed physical therapists and patients for six weeks, in order to identify satisfaction with physical therapy. The statistical significance of the management plan with regard to costs and cost estimation and payment methods was determined and managed according to the operating principals of HBPT, eligibility criteria, number of visits, treatment time, and team approach.

Results: Through the survey all groups of patients and physical therapists recognized the need for HBPT. They felt that the most desirable methods for activation of physical therapy visits involve precise diagnosis and evaluation through a team approach. While making regular visits to the patient three times a week, an expert visiting physical therapist with 3 to 5 years of experience in the clinical field could provide central nerve developmental treatment in less than 60 minutes; this service could be provided at a reasonable cost, minimizing unnecessary hospital visits, reducing time, medical expenses and facilitating a quick recovery due to psychological satisfaction resulting from a decrease in the psychological anxiety patients often experience in medical institutions.

Conclusion: Based on the study results provided above, if HBPT is to be introduced, appropriate pricing and programs should be based on the results of pilot projects.

Keywords: Home-based physical therapy, Cerebrovascular disease, Team approach

\section{서 론}

우리나라는 생활 수준이 향상되고 의료기술이 발전함에 따라 평균 수명이 연장되고 노인 인구의 증가율이 높아지면서 만성 질환의 발 병률 역시 증가하고 있다. 보건복지부의 "2011년도 노인실태조사" 에 따르면 노인의 $88.5 \%$ 가 만성 질환을 갖고 있는 것으로 나타났고, 평균 2.5 개의 만성질환을 가지고 있었다. 또한 2 개 이상의 만성 질환을 복 합적으로 가진 노인도 $68.3 \%$ 나 되었으며, 3 개 이상 지닌 경우도 $44.3 \%$ 에 달했다. 2011년 통계에 따르면 우리나라 국민의 만성질환에 의한 사망률을 살펴본 결과 인구 10 만 명당 암 112.8 명으로 가장 높았고그 다음으로 뇌혈관질환 37.8 명 순으로 나타났다.' 뇌혈관질환은 대뇌의 혈액순환 장애가 중추신경계를 침범해 신경학적 장애를 발생시키며 적어도 24 시간 이상 지속된다. 뇌혈관질환의 증상은 근육의 약화와 감각의 변화, 균형의 불안정성, 보행 능력의 저하, 운동 기능장애 등 병
변 부위에 따라 다양하며 운동기능의 장애는 신체적, 심리적인 고통 을 겪게 된다.5.5이와 같이 뇌혈관질환은 장기간의 집중적인 의료처치 와 재활치료를 요구할 뿐 아니라 잠재적 장애나 영구적 기능제한을 가진 상태에서 예후가 불확실하여 신체적 돌봄을 위한 물질적, 인적 요구를 높여 의료비 상승을 초래하고 이는 가족은 물론 사회 전체에 도 큰 부담으로 작용하고 있다. ${ }^{6}$

최근 만성질환 발생 증가에 따른 노인 의료비 상승에 대한 대안으 로 만성질환에 적합한 재가·지역사회서비스가 급성장하여 다양한 요양시설, 재가.지역사회서비스가 개발되었고 전문요양병상, 단기입 소병상, 낮 병원, 방문서비스 등 비용이 저렴하면서도 심리적 안정을 주는 방향으로 선회하고 있다. 방문의료는 만성질환 또는 급성기 질 환으로 인해 병원에서 급성치료를 종료한 이후 병세는 안정되었으나 일상생활수행능력에 제한이 발생한 노인에게 재가서비스를 제공하 여 신체적 능력 향상 및 회복을 통해 일상생활능력을 극대화시키기 
위해 필요한 제도로 외국에서는 재활 팀 접근법을 사용하여 장애에 대한 정확한 진단과 기능평가를 수행하고 신체적, 감정적, 지각적, 인 지적, 그리고 환경을 포함한 삶의 전체를 평가하여 포괄적인 치료를 시행으로 노인, 장애인, 가족 및 사회적으로 긍정적인 제도로 인식되 고 있다. 이 중 방문 물리치료는 의사의 처방을 기초로 하여 가정에 서 물리치료를 제공하는 것으로, 뇌혈관질환을 비롯한 만성질환, 척 수손상, 수술 후 조기 퇴원 환자 등을 대상으로 통증치료 및 전기치 료, 운동 치료, 일상생활동작훈련 등을 시행하는 것이다. Sunwoo ${ }^{8}$ 는 병원, 재활요양병원, 전문요양시설, 외래재활시설, 가정방문서비스 등 을 통해 재활서비스 제공이 필요하다고 하였고, 미국의 Duncan 등9 은 만성 뇌혈관환자에게 제공된 체계적인 방문치료 프로그램은 지 구력, 균형능력, 기능향상에 효과가 있다는 결과를 발표하였으며, 일 본은 방문 평가에서 환자와 보호자 모두에서 신체기능의 유지 및 개 선, 정신적 부담경감 등 효과가 좋은 항목이 방문물리치료 시행이라 고 하였다.10 요컨대 방문물리치료가 의료전달체계의 한 영역으로 정 착된다면, 합리적인 비용으로 양질의 서비스를 제공할 수 있고, 병원 인력 및 시설의 효율적 활용 및 장기 입원으로 인한 여러 가지 문제점 을 예방할수 있을 것이다.11

그럼에도 불구하고 현재 우리나라에는 법적으로 방문 재활을 인 정하지 않으며 국민건강보험의 급여를 적용 받지 못하는 실정으로 일부 제한적으로 방문건강관리사업의 형태로 취약계층을 대상으로 한 방문서비스가 시행되고 있으나 이는 정확한 의미의 방문 재활서 비스로 보기에는 한계가 있다.

이에 본 연구에서는 방문 물리치료의 도입 필요성과 이에 대한 다 양한 의견을 조사하여 방문물리치료의 도입의 근거를 제시하고 제 도 정착을 위한 방안의 정책적 토대를 마련하고자 한다.

\section{연구방법}

\section{1. 연구 대상}

본 연구는 서울, 인천, 경기, 부산, 전북, 전남, 경북, 경남, 강원, 충청, 제 주지역의 대학병원 및 종합병원, 재활요양병원, 의원, 보건소, 복지관 등에 근무하는 물리치료사와 뇌혈관질환을 진단받고 재활치료를 받 고 있는 환자를 대상으로 2012년 3월 19일부터 4월 30일까지 약 6주 동안자기기입식 방법으로 설문조사를 실시하였다.

\section{2. 조사 도구}

본 연구의 설문지는 방문물리치료의 도입방안에 대해 $\mathrm{Yang}^{10}$ 의 "가정 방문물리치료제도에 관한 실증적 연구"와 Moon ${ }^{12}$ 의 "가정물리치료 사제도 도입 요구에 관한 연구”를 참고하여 환자용과 물리치료사용 으로 각각 나누어 제작하였다. 환자를 대상으로 한 설문지는 물리치
료 이용경험에 대한 10 문항, 물리치료 이용 만족도에 대한 4 문항, 방 문물리치료에 대한 11 문항, 응답자의 기초정보 7 문항으로 구성되었 고, 물리치료사를 대상으로 한 설문지는 물리치료 이용 경험에 대한 5 문항, 물리치료 이용 만족도에 대한 4 문항, 방문물리치료에 대한 16 문항, 응답자의 기초정보 6 문항으로 구성되었다. 설문지는 환자용 600 부와 물리치료사용 500 부를 배부하였고, 환자용 583 부, 치료사 용 476 부를 각각 회수하였다.

\section{3. 연구 분석}

본 연구는 회수한 설문지를 바탕으로 무응답 결측값을 처리하고 코 딩 과정을 거친 후 SPSS 17.0 for Windows 프로그램을 이용하여 통계 처리 하였다. 통계분석은 첫째, 연구대상자의 일반적 특성, 재활치료 에 대한 전반적인 내용과 만족도, 방문물리치료의 인식 정도와 필요 성, 참여 및 이용의사에 관한 사항, 운영방안에 관한 사항 등을 빈도 와 백분율로 산출하여 빈도분석 하였다. 둘째, 물리치료 만족도를 확 인하기 위해 일 표본 t-검정으로 통계적으로 유의성을 알아보았다. 셋 째, 방문물리치료 운영주체, 자격기준, 방문 횟수, 치료 시간, 팀 접근 방법, 비용과 비용 산정방법과 비용 지불방법 등 운영방안에 대해 카 이제곱 검정을 실시하여 통계적 유의성을 확인하였다. 통계적 유의성 을 검정하기 위한 유의수준 $a=0.05$ 로 하였다.

\section{결 과}

\section{1. 방문물리치료의 도입 방안 조사}

1) 환자에 대한 조사분석 결과

(1) 환자의 일반적 특성

환자의 일반적 특성으로 성별은 남성 $43.9 \%$, 여성 $55.4 \%$ 이고 평균 연 령은 61세이다. 결혼여부는 연령 분포상 기혼이 많았고, 학력은 고졸 $34 \%$, 대졸 $27.3 \%$ 순이었고, 월 평균 수입은 200만 원에서 300 만 원 미만 이 가장 많았다. 치료적 특성으로 치료비는 자녀 $44.3 \%$, 본인 부담 $23.3 \%$ 순으로 부담되었고, 간호나 수발을 담당하는 자는 유료 간병인 $53.3 \%$, 배우자 $22 \%$ 순이었고, 치료받는 형태는 재활요양병원 및 의원 입원 $63.3 \%$, 재활요양병원 및 의원 외래 $18.9 \%$ 순이었다. 또한 환자가 진단받은 질환은 복수응답으로 뇌혈관질환 $53.2 \%, 21.4 \%$, 관절염 $13.4 \%$ 라고 응답하였다.

\section{(2) 방문물리치료의 인식 정도와 필요성}

방문물리치료의 인식 정도는 환자의 $68.8 \%$ 이 방문물리치료에 대하 여 모른다고 응답하였고, 알고 있다는 $29.8 \%$ 로 방문물리치료에 대한 인식 정도가 부족함을 확인할 수 있었다 반면에 방문물리치료에 필 요성은 “필요하다"는 응답은 $84.2 \%$ 였고, 방문물리치료에서 가장 필요 
한 치료로 복수응답으로 중추신경계발달치료, 일상생활동작훈련, 관절가동범위운동, 가정운동프로그램 등으로 조사되었다.

\section{2) 물리치료사에 대한 조사분석 결과}

(1) 물리치료사의 일반적 특성

물리치료사의 일반적 특성으로 성별은 남성 $41.4 \%$, 여성 $58.2 \%$ 로 평 균 연령은 29세로 결혼여부는 미혼이 많았으며, 학력은 3 년제 대학졸 업 $47.7 \%, 4$ 년제 대학졸업 $42.6 \%$, 대학원 졸업 $8.6 \%$ 순이었다. 근무 장 소로는 재활 및 요양병원 $44.5 \%$, 복지관, 의원 순으로 고령사회로 노 인 인구가 증가되어 재활 및 요양병원의 증가가 원인으로 생각되며, 근무경력은 평균 5.5 년이었다. 치료적 특성은 1 일 재활치료 건수는 11 건에서 20 건 $69.1 \%$ 이며 1 인 치료 평균 재활치료시간은 30 분 이상 45 분 미만이 $47.3 \%$, 물리치료의 유형은 운동치료가 $67.2 \%$ 로 가장 많았고, 물리치료사가 치료하는 질환은 복수응답으로 뇌혈관질환 $80.1 \%$ 이 많았고, 치매 $20.1 \%$, 파킨슨병 $15.5 \%$ 순으로 응답하였다.

\section{(2) 방문물리치료의 인식 정도와 필요성}

방문 물리치료에 대한 인식 정도를 분석한 결과 물리치료사의 $87.6 \%$ 가 방문 물리치료를 알고 있었고, 필요성에 대한 응답도 "필요하다" 가 $96 \%$, “필요하지 않다”가 $4 \%$ 였다. 방문 물리치료에 대한 참여의사를 묻는 문항에서는 $73.3 \%$ 이 “참여하겠다”라고 응답하였고 참여의사를 밝힌 물리치료사에게 참여를 활성화하기 위해 제도적으로 개선되어 야 할 점을 조사한 결과, 적절한 월 급여 보장과 정규직과 같은 근무 환경과 의사의 장기처방에 의한 물리치료사의 자율적 물리치료 실 시, 안정적인 근무 여건 순으로 높은 응답률을 보였다.
3) 물리치료 만족도

(1) 환자군 물리치료 만족도

물리치료 만족도에 대해 전반적으로 '보통’ 이상으로 만족하고 있으 며, 이는 통계적으로 유의하였다(Table 1).

\section{(2) 물리치료사군 물리치료 만족도}

물리치료사는 물리치료 제공에 대해 전반적으로 '보통' 이상의 물리 치료를 제공하고 응답하였으며 제공하는 물리치료가 효과가 있다고 응답하였다(Table 2).

\section{4) 방문물리치료의 운영방안}

(1) 방문물리치료의 운영방안 교차분석

환자군과 물리치료사군간의 방문물리치료서비스의 운영주체, 자격 기준, 방문 횟수, 치료 시간, 팀 접근방법, 비용과 비용 산정방법과 비 용 지불방법 등이 통계적으로 유의하였다. 방문물리치료의 인식 정 도는 물리치료사군은 높은데 비해 환자 군은 낮아 물리치료사군과 환자군간의 유의한 차이가 있고, 방문물리치료 필요 유무에 환자군 과 물리치료사군의 응답결과는 대체적으로 필요하다는 응답이 많았 으며, 집단간 응답 비율에 통계적으로 유의한 차이가 있었다. 방문물 리치료 비용에서 환자군과 물리치료사군에서 환자군의 경우 1 만 5 천원 이하 비용이 적정하다는 응답이 전체 응답자의 절반을 넘는 반 면 물리치료사군의 경우 1 만 5 천 원 이상의 비용이 적정하다는 응답 이 전체 $80 \%$ 를 차지하고 있었다(Table 3).

\section{(2) 방문물리치료 비용의 주성분 분석}

방문물리치료의 비용에서 주성분 분석으로 일부 설문 문항들 사이

Table 1. Physical therapy satisfaction of the patient group

\begin{tabular}{|c|c|c|c|c|c|c|c|}
\hline Variables & 5 & 4 & 3 & 2 & 1 & Mean $\pm S D$ & p-value \\
\hline Satisfaction & 184 & 265 & 107 & 14 & 2 & $4.08 \pm 0.80$ & $0.000^{*}$ \\
\hline Satisfaction with therapeutic tool & 119 & 235 & 181 & 29 & 2 & $3.78 \pm 0.85$ & $0.000^{*}$ \\
\hline Satisfaction with treatment time & 104 & 181 & 175 & 82 & 26 & $3.45 \pm 1.01$ & $0.000^{*}$ \\
\hline Satisfaction with facilities and space & 118 & 232 & 160 & 48 & 12 & $3.69 \pm 0.96$ & $0.000 *$ \\
\hline
\end{tabular}

${ }^{*} \mathrm{p}<0.001$. 5: Completely true, 4: Very true, 3: Moderately true, 2: Not true, 1: Absolutely not true.

Table 2. Physical therapy satisfaction of the physical therapist group

\begin{tabular}{|c|c|c|c|c|c|c|c|}
\hline Variables & 5 & 4 & 3 & 2 & 1 & Mean $\pm S D$ & p-value \\
\hline Get better after PT & 104 & 312 & 58 & 2 & 0 & $4.09 \pm 0.59$ & $0.000^{*}$ \\
\hline Provide enough PT to patients & 24 & 174 & 200 & 73 & 5 & $3.29 \pm 0.82$ & $0.000^{*}$ \\
\hline PT recipient satisfaction is high & 52 & 287 & 124 & 11 & 2 & $3.79 \pm 0.68$ & $0.000^{*}$ \\
\hline $\begin{array}{l}\text { Help with prevent and treatment about } \\
\text { diseases chronic }\end{array}$ & 191 & 236 & 39 & 9 & 1 & $4.28 \pm 0.71$ & $0.000^{*}$ \\
\hline
\end{tabular}

PT, Physical therapy.

${ }^{*} p<0.001$. 5: Completely true, 4: Very true, 3: Moderately true, 2: Not true, 1: Absolutely not true. 
Table 3. Management plan of home-based physical therapy

\begin{tabular}{|c|c|c|c|c|c|}
\hline Item & Division & Patient (\%) & PT (\%) & Total (\%) & $\chi^{2}$ \\
\hline \multirow[t]{2}{*}{ Perception of HBPT } & Know & $173(30.1)$ & $417(87.6)$ & $590(56.1)$ & $x^{2}=349.958^{*}$ \\
\hline & Do not know & $401(69.7)$ & $59(12.4)$ & $460(43.8)$ & \\
\hline \multirow[t]{2}{*}{ Necessity of HBPT } & Need & $491(86.0)$ & $456(96.0)$ & $948(90.5)$ & $x^{2}=30.436^{*}$ \\
\hline & Do not need & $80(14.0)$ & $19(4.0)$ & $99(9.5)$ & \\
\hline \multirow[t]{5}{*}{ Operator of HBPT } & State and local governments & $308(54.6)$ & $245(51.6)$ & $553(53.2)$ & $\chi^{2}=50.998^{*}$ \\
\hline & Corporation and member associations & $44(7.8)$ & $75(15.8)$ & $119(11.5)$ & \\
\hline & Hospital & $86(15.2)$ & $32(6.7)$ & $118(11.4)$ & \\
\hline & Welfare & $50(8.9)$ & $19(4.0)$ & $69(6.6)$ & \\
\hline & PT personal & $76(13.5)$ & $104(21.9)$ & $180(17.3)$ & \\
\hline \multirow[t]{5}{*}{ Qualification criteria of HBPT } & PT licensed & $69(12.0)$ & $48(10.1)$ & $117(11.2)$ & $x^{2}=27.493^{*}$ \\
\hline & 3 years of clinical experience PT & $206(36.0)$ & $220(46.2)$ & $426(40.6)$ & \\
\hline & 5 years of clinical experience PT & $200(34.9)$ & $170(35.7)$ & $370(35.3)$ & \\
\hline & 10 years of clinical experience PT & $60(10.5)$ & $30(6.3)$ & $90(8.6)$ & \\
\hline & Anyone educated & $38(6.6)$ & $8(1.7)$ & $46(4.4)$ & \\
\hline \multirow[t]{5}{*}{ Desired number of HBPT } & Once a week & $28(4.9)$ & $11(2.3)$ & $39(3.7)$ & $x^{2}=47.422^{*}$ \\
\hline & Twice a week & $139(24.2)$ & $147(30.9)$ & $286(27.3)$ & \\
\hline & Thrice a week & $285(49.7)$ & $282(59.4)$ & $567(54.1)$ & \\
\hline & Four times a week & $33(5.7)$ & $12(2.5)$ & $45(4.3)$ & \\
\hline & Five times a week & 89 (15.5) & $23(4.8)$ & $112(10.7)$ & \\
\hline \multirow[t]{6}{*}{ Treatment time of HBPT } & Less than 30 minutes & $45(7.9)$ & $40(8.4)$ & $85(8.1)$ & $\chi^{2}=88.584^{*}$ \\
\hline & Less than 60 minutes & $321(56.1)$ & $380(79.8)$ & $701(66.9)$ & \\
\hline & Less than 90 minutes & $156(27.3)$ & $52(10.9)$ & $208(19.8)$ & \\
\hline & Less than 120 minutes & $29(5.1)$ & $3(0.6)$ & $32(3.1)$ & \\
\hline & Greater than 120 minutes & $15(2.6)$ & $1(0.2)$ & $16(1.5)$ & \\
\hline & Etc. & $6(1.0)$ & $0(0.0)$ & $6(0.6)$ & \\
\hline \multirow[t]{5}{*}{ HBPT team approach method } & Individual PT & $127(21.8)$ & $47(9.9)$ & $174(16.4)$ & $x^{2}=61.624^{*}$ \\
\hline & 2 person PT & $46(7.9)$ & $45(9.5)$ & $91(8.6)$ & \\
\hline & PT + Nurse & $55(9.4)$ & $59(12.4)$ & $114(10.8)$ & \\
\hline & $\mathrm{PT}+\mathrm{OT}$ & $199(34.1)$ & $137(28.8)$ & $336(31.8)$ & \\
\hline & $\mathrm{PT}+\mathrm{OT}+$ Nurse & $137(23.5)$ & $186(39.1)$ & $323(30.5)$ & \\
\hline \multirow[t]{5}{*}{ HBPT cost } & $5,000-10,000$ won & $41(16.63)$ & $96(30.6)$ & $137(24.4)$ & $\chi^{2}=19.713^{*}$ \\
\hline & $10,000-15,000$ won & $79(30.8)$ & $81(25.8)$ & $157(28.0)$ & \\
\hline & $15,000-20,000$ won & $61(24.7)$ & $65(20.7)$ & $126(22.5)$ & \\
\hline & Greater than 20,000 won & $50(20.2)$ & $63(20.1)$ & $113(20.1)$ & \\
\hline & Etc. & $19(7.7)$ & $9(2.9)$ & $28(5.0)$ & \\
\hline \multirow[t]{5}{*}{ Way of calculation HBPT cost } & Hospital treatment & $99(17.5)$ & $15(3.2)$ & $114(10.9)$ & $x^{2}=237.544^{*}$ \\
\hline & Outpatient treatment & $107(18.9)$ & $34(7.2)$ & $141(13.5)$ & \\
\hline & Outpatient treatment + Costs & $121(21.3)$ & $89(18.7)$ & $210(20.2)$ & \\
\hline & Outpatient treatment + Cost + Visit allowance & $132(23.3)$ & $318(66.9)$ & $450(43.2)$ & \\
\hline & Fixed cost & $108(19.0)$ & $19(4.0)$ & $127(12.2)$ & \\
\hline \multirow[t]{5}{*}{ Way of payment HBPT cost } & A fixed amount per visit & $97(17.2)$ & $43(9.1)$ & $140(13.5)$ & $x^{2}=31.992^{*}$ \\
\hline & Salary based on number of visits & $235(41.7)$ & $241(50.8)$ & $476(45.9)$ & \\
\hline & The amount due to condition of the patient & $97(17.2)$ & $55(11.6)$ & $152(14.7)$ & \\
\hline & Depending on the time differential treatment & $79(14.0)$ & $58(12.2)$ & $137(13.2)$ & \\
\hline & Depending on the method differential treatment & $55(9.8)$ & $77(16.2)$ & $132(12.7)$ & \\
\hline
\end{tabular}

PT, Physical therapy; OT, Occupational therapy; HBPT, Home Based Physical therapy. ${ }^{*} p<0.001$

에 유사한 응답 패턴 결과 월수입이 높은 사람이 방문물리치료의 비 용에서 높은 금액을 지불하며 월수입이 없거나 여성인 경우에 방문 물리치료의 비용에서 가장 적은 금액을 응답하였다(Figure 1). 물리치
료 만족도가 높을수록 방문물리치료 비용에서 높은 금액을 지불하 며 물리치료 만족도가 낮을수록 방문물리치료 비용에서 적은 금액 을 응답하였다(Figure 2). 


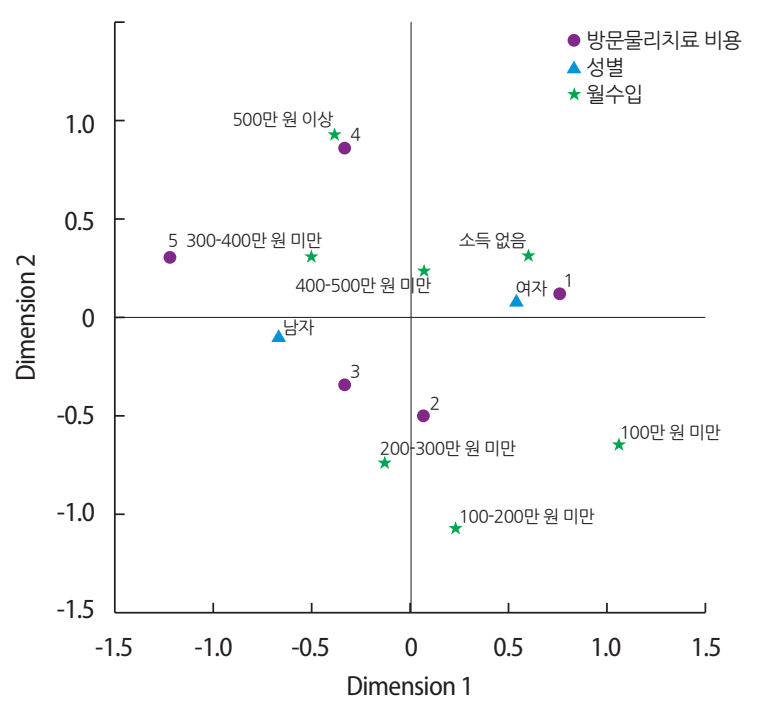

Figure 1. The cost of Home-based physical therapy depends on Monthly income or Sex.

\section{고 찰}

본 연구는 병원에서 물리치료를 받고 있는 환자와 치료를 시행하는 물리치료사에게 각각 설문조사를 실시하여 방문물리치료의 인식 정 도와 필요성에 대하여 알아보았다.

방문물리치료 인식 정도는 물리치료사는 $70 \%$ 이상이 알고 있는 데 반해, 환자는 $23 \%$ 에서만 알고 있다는 응답을 하여 환자와 물리치 료사간에 유의한 차이를 보였다. 이는 $\mathrm{Kim}^{13}$ 의 연구에서 방문물리치 료의 물리치료사의 인식 정도는 높은 반면 환자들의 대부분은 인식 정도가 부족하다고 보고한 결과와 일치하였다. 방문물리치료의 필요 성은 설문에 응답한 환자 중 $84.2 \%$, 물리치료사는 $96 \%$ 가 '필요하다’ 고 하였다. Jung 등 ${ }^{5}$ 도 환자와 물리치료사가 방문 물리치료의 필요성 에 동의하고 있다고 보고하였고, $\mathrm{Kim}^{14}$ 과 $\mathrm{Han}^{17}$ 의 연구에서도 환자와 보호자가 방문물리치료가 꼭 필요하다고 하였다. 또한, Yang ${ }^{10}$ 은 환자 와 보호자 $96.7 \%$, 물리치료사 $100 \%$ 가 필요하고 $\mathrm{Moon}^{12}$ 은 물리치료 사 $99 \%$, Lee $^{16}$ 도 환자 $77.3 \%$ 가 필요성에 동의하였다. 즉, 방문 물리치료 의 필요성에서는 물리치료사를 비롯하여 의사, 간호사, 환자, 보호자 등에서 높은 동의를 보였다. 또한, 물리치료사의 방문물리치료 참여 에 대한 의사를 묻는 설문에서는 응답한 물리치료사 중 $73.3 \%$ 가 참 여하겠다고 하였다. 이는 Yang ${ }^{10}, \mathrm{Kwon}$ 과 Hwang ${ }^{17}$ 도 물리치료사참여 의사에서 높은 결과를 보인 것과 일치하는 것이었고, Lee ${ }^{16}$ 의 연구에 서는 방문 물리치료에 대한 의사들 참여의사 역시 $90 \%$ 이상으로 높게 나타나고 있었다.

방문 물리치료의 운영주체를 묻는 조사에서는 환자와 물리치료사 모두 국가나 지방자치단체를가장 선호하였고, 방문 물리치료의 의료

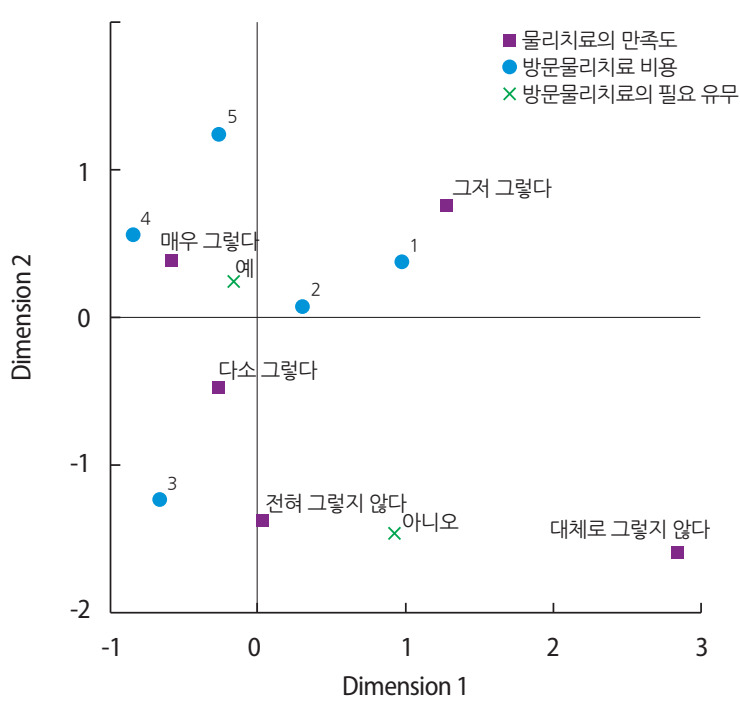

Figure 2. The cost of Home-based physical therapy depends on Physical therapy satisfaction.

인력 구성에 대한 조사에서는 물리치료사와작업치료사가 방문 해야 한다는 물리치료사군과 물리치료사와 작업치료사와 간호사가 함께 방문 해야 한다는 환자 군의 응답으로 차이를 보였다. 선행연구에서 도 의료인력 구성과 접근방식에 대해 다양한 의견을 보였는데, Yang ${ }^{10}$ 은 방문물리치료활성화를 위해 가장 바람직한 방법은 팀 접근방식 으로 전문가의 협조가 필요하다고 하였고, Yoon ${ }^{18}$ 은 물리치료사와작 업치료사의 팀 접근의 치료형태가 가장 이상적이라고 하였으며, $\mathrm{Kim}^{19}$ 은 재활전문가들 전원 팀 접근방식에 높은 관심을 보였다고 제 시하였다. 또한, Park 등 ${ }^{20}$ 은 이상적인 팀 접근방식은 미국과 일본처럼 환자 별로 관련된 전문의와 물리치료사, 간호사, 작업치료사, 언어치 료사, 사회복지사, 보호자들과의 상호협조체계가 이루어져 함께 참 여하는 모델로 변화 해야 한다고 하였다. $\mathrm{Kim}^{21}$ 는 물리치료사와작업 치료사가 함께 방문하고 $\mathrm{Kim}^{22}$ 는 가정간호에서 물리치료사와작업치 료사 등이 포함된 팀 접근방식에 대해 높은 관심을 보여주고 있었다.

방문 물리치료 전문 인력의 자격요건은 물리치료사는 3 년 $46.2 \%, 5$ 년 $35.7 \%$ 의 임상경험과 방문물리치료교육을 받은 치료사가 적절하 다고 응답하였고, 환자의 경우 3 년 $35.3 \%, 5$ 년 $34.3 \%$ 의 임상경험과 방 문물리치료교육을 받은 치료사가 적절하다고 응답하였다. 방문물리 치료의 적당한 방문 시기는 물리치료사와 환자 모두 주 3 회를 가장 선호하였고, 방문물리치료 소요시간에서 병원은 1 인당 물리치료 평 균 치료시간은 30 분에서 45 분 미만이 $47.3 \%$, 방문물리치료는 30 분에 서 60 분 미만이 $55.1 \%$ 로 조사되었다.

방문물리치료의 적정비용과 관련해서는 물리치료사는 2 만 5 천 원 에서 2 만 원이 $48.9 \%$ 로 많았고, 환자는 1 만 5 천 원에서 2 만 원이 $30.3 \%$ 순으로 조사되어 환자와 물리치료사간의 차이가 크다는 점을 보여주 
었다. 이 같은 결과는 향후 방문물리치료의 비용 산정에 있어서 제공 되는 서비스에 따라 적정한 치료비용을 산정하고 이에 대한 이용자 와 제공자 간의 의견을 수렴하여 최종적으로 의견합의를 이루어야 할 필요성을 보여주는 것으로 사료된다.

방문 물리치료 비용산정방법은 물리치료사의 경우 응답자 중 $66.8 \%$ 가 현재 외래치료비에 교통비와 수당을 더한 금액을 선호하였 고, 환자의 경우 $22.6 \%$ 가 선호하였다. 현재 가정간호수가체계는 병원 급 기준으로 기본 방문료 32,430 원에서 $20 \%$ 는 환자 본인부담이며, 교 통비는 7,150원을 전액 본인이 부담하고 행위별수가도 $20 \%$ 는 환자 본 인이 부담하는 것으로 구성되어 있는데, 적정한 방문물리치료 비용 을 산정하기 위해서는 가정간호사제도의 자료를 기초로 하고 방문 물리치료의 경제성 평가 연구를 실시하여 그 결과를 바탕으로 현실 적인 방문물리치료 비용을 산정하는 것이 바람직하다고 사료된다.

본 연구는 방문 물리치료 서비스의 도입을 위한 근거를 제시하고 자 서비스 이용자인 만성질환 중 뇌혈관질환을 않고 있는 환자와 서 비스 제공자인 물리치료사를 대상으로 설문조사를 실시하였고 그 결과, 방문 물리치료 서비스의 이용자인 환자와 제공자인 물리치료 사 모두에서 방문 물리치료의 필요성을 인정하고 있었고, 국가 및 지 방자치단체가 주체가 되어 운영하며 정부의 정책에 의해 공공기관에 서 시행된 방문물리치료가 신뢰를 준다고 생각하고 있었으며, 방문 물리치료의 활성화를 위해 가장 바람직한 방법은 방문을 원하는 환 자에게 의사, 간호사, 물리치료사, 작업치료사, 사회복지사가 포함된 팀 접근방식으로 3 년에서 5년 이상 임상경험이 있는 방문물리치료사 가 주 3 회로 규칙적으로 방문하여 환자에게 가장 필요한 물리치료인 중추신경계발달치료, 일상생활동작훈련, 관절가동범위운동 등의 치 료를 60 분 미만으로 제공받는 것으로 나타났다.

향후 방문물리치료 도입을 위해서 의료보험 수가책정을 위한 방 문 물리치료의 경제성 분석과 질 높은 서비스를 제공할 수 있는 인력 양성을 위한 교육프로그램을 개발하고 보건의료 분야의 다양한 의 견 수렴과 교환을 위한 공청회 실시 등의 중장기적 계획을 수립하여 실행할 필요가 있다. 또한 방문 물리치료 서비스의 이용자인 환자와 보호자를 대상으로 적극적인 홍보를 통해 방문물리치료의 필요성을 인식시키고 본 연구결과를 토대로 방문 물리치료 도입을 위한 지속 적인 연구와 정책 반영을 위한 노력이 필요할 것으로 사료된다.

\section{REFERENCES}

1. The survey of living condition and welfare needs of Korean older persons. Ministry of health and welfare. 2011:285-297

2. Yang DJ, Park SK, Kang JI, et al. Effects of changes in postural alignment on foot pressure and balance of patients with Stroke. J Kor Phys Ther.
2014;24(4):247-52.

3. Jung JH, Kim JH. Correlation between bilateral reciprocal leg press test and the balance in chronic stroke patient. J Kor Phys Ther. 2013; 25(4):180-6.

4. Verheyden G VL, Truijen S, et al. Trunk performance after stroke and the relationship with balance, gait and functional ability. Clin Reha. 2006;20(5):451-8.

5. Jung BO, Lee CR, Kim KJ, et al. The analysis of need with homebound disabled persons in a country area. J Kor Phys Ther. 2006;13(4):43-62.

6. Kim HJ, Lee KH, Lee, JS. Introduction of home rehabilitation services in long-term care insurance system for the elderly. KSOT. 2010;18(3): 2335.

7. Yang YA, An SJ, Park YH, et al. A study of visiting rehabilitation service and implementation method. J Kor Asso Occu The Poli for Aged Indu. 2011;3(1):59-70.

8. Sunwoo D. A study on model development of integrated health and social service system to improve activities of daily living of older persons. Korea Institute for Health and Social Affairs. 2000.

9. Duncan P, Richards L, Wallace D, et al. A randomized, controlled pilot study of a home-based exercise program for individuals with mild and moderate stroke. Stroke; j cerebral circulation. 1998;29(10):2055-60.

10. Yang YA. A Positive Study on Home-Visiting Physical Therapy System. Hanyang university. Dissertation of Master's Degree. 1997.

11. Yang YA, Kim YS. A study on the needs about Nursing Home Care Physical Therapy System. Bulletin of the Institute of Environmental \& Industrial Medicine. 2000;9(1):119-28.

12. Moon TS. Research of the introduction of home physical therapist system. Yeonsei university. Dissertation of Master's Degree. 2001.

13. Kim GY. A study on the introduction of home-based physical therapy rehabilitation services. Eulji University. Dissertation of Doctorate Degree. 2013.

14. Kim DM.The Necessity to Introduce Home Visiting Physiotherapy. J Kor acad phys ther. 1996;3(2):163-75.

15. Han DU. The degree of demand and features of service required for home visiting physical therapy. Chungnam National University. Dissertation of Master's Degree. 1999.

16. Lee JB. The study of home-based physical therapy to patient's and doctor's cognitive map to demend. Gachon University. Dissertation of Master's Degree. 2004.

17. Kwon HJ, Hwang SS. A review on the needs and understanding about the home physical therapy system. J Kor Soci heal Scie. 2005;2(2):83-99.

18. Yoon TH. A study of the inclusion of home-based physical therapy services in the long term care insurance. Hanyang university. Dissertation of Doctorate Degree. 2009.

19. Kim HJ. A study for the Introduction of home rehabilitation servicesin long-term care insurance system fot the elderly. Injae university. Dissertation of Doctorate Degree. 2010.

20. Park JH Seong YH, Song MS, et al. The classification of standard nursing activities in Korea. J Kor Acad Nurs. 2000;30(6):1411-26.

21. Kim MS. The study of efficient way of home-based physical therapy. Samyook University. Dissertation of Master's Degree. 2011.

22. Kim SJ. Historical study of home care service in a WonJu christian hospital. Seoul National University. Dissertation of Master's Degree. 1991. 